Not Even the Past: The Joint Influence of Former Leader and New Leader during Leader Succession in the Midst of Organizational Change

Helen H. Zhao

University of Hong Kong

Scott E. Seibert

University of Iowa

M. Susan Taylor

University of Maryland

Cynthia Lee

Northeastern University

Wing Lam

The Hong Kong Polytechnic University 


\title{
Not even the past: The joint influence of former leader and new leader during leader succession in the midst of organizational change
}

\begin{abstract}
Leader succession often occurs during organizational change processes, but the implications of leader succession, in terms of reactions to the change, rarely have been investigated. Employee attitudes and behaviors during organizational change may be influenced jointly by a former leader who recently has transitioned out of the team and the new leader who recently has transitioned into it. We predict an interaction between former and new leaders' transformational leadership on employees’ behavioral resistance to and support for change. Based on contrast effect theory, a highly transformational former leader constrains the potential effectiveness of the new leader, but a former leader low in transformational leadership enhances this potential effectiveness. We also propose conditional indirect effects transmitted through commitment to the changing organization. Our research was conducted in a large Chinese hospitality organization that was implementing radical organizational change, during which virtually all aspects of processes and products are changed. We collected a 2-wave multisource data from employees who had recently experienced a leader succession and their newly assigned leaders. Based on a final sample of 203 employees from 22 teams, we find empirical support for the proposed interaction effects. The conditional indirect effects were also consistent with our expectations, but the effect on behavioral resistance to change was stronger than the effect on behavioral support for change.
\end{abstract}

Keywords: Leader Succession; Organizational Change; Transformational Leadership 
Leader succession is a common organizational process, in which a former leader transitions out of and a new leader transitions into the leadership role (Ballinger \& Schoorman, 2007). Leader successions are particularly frequent during organizational change (Gilmore, 2003; Kanter, Stein, \& Jick, 2003; Watkins, 2003), because changing organizations often must fill job vacancies caused by restructuring or managerial turnover, or they need new leaders to accomplish strategic goals, such as bringing in new resources and meeting new business demands (Arthaud-Day, Certo, Dalton \& Dalton, 2006; Barker, Patterson, \& Mueller, 2001). In recent years, the role of leadership during organizational changes has attracted considerable scholarly attention (e.g., Bommer, Rich, \& Rubin, 2005; Herold, Fedor, Caldwell, \& Liu, 2008; Hill, Seo, Kang, \& Taylor, 2011; Oreg \& Berson, 2011; Seo, Taylor, Hill, Zhang, Tesluk, \& Lorinkova, 2012). Yet, prior studies often overlooked the fact that many change efforts are actually led by frontline leaders who are new in their roles.

This neglect of leader succession marks not only the organizational change literature but also broader leadership research. Most previous studies of leader succession focus on the impact of top management team succession on the organization, such as how CEO succession can explain changes in organizational performance, or how contextual factors alter the impact of succession (for reviews, see Giambatista, Rowe, \& Riaz, 2005; Kesner \& Sabora, 1994). The change of leaders at lower management levels, which as Ballinger and Schoorman (2007) note are more relevant than CEO succession to employees’ everyday lives, is still very limited. Surprisingly, despite extensive research on the effects of leader behaviors, it remains unclear how the effects of a new leader's behaviors might be altered by the former leader.

We thus introduce a contrast-based theoretical perspective to understand how employees relate their past (i.e., former leader) to their present (i.e., new leader). Contrast effect theory 
suggests that people react to their present experiences in a direction opposite their past experiences. When the present is in contrast with a negative past experience, people react less negatively to the present; when the present is in contrast with a positive past experience, they react less positively to the present (Frederick \& Loewenstein, 1999; Markman \& McMullen, 2003). We use this theoretical framework to understand how employees' reactions to their new leader may be conditioned by their experience with their former leader. We focus on transformational leadership of both leaders, because "transformational leadership is, at its core, about issues around the processes of transformation and change (Bass \& Riggio, 2006, p. 225).” Transformational leadership thus is able to positively influence or "transform” employees' attitudes toward change and foster positive employee reactions to organizational change (Bommer et al., 2005; Herold et al., 2008; Seo et al., 2012). During a leader succession process, the transformational leadership of both the new leader and the former leader jointly influence employees’ reactions to change (Hollenbeck, DeRue \& Nahrgang, 2015). We focus on behavioral resistance to and behavioral support for organizational change, to capture the reactive and proactive aspects of employee behaviors, respectively. Whereas behavioral resistance to change involves attempts to undermine the change and maintain the status quo, behavioral support for change entails actively trying to solve problems to help implement changes. These behaviors have been studied together but as two separate constructs in prior literature (Seo et al., 2012), and the inclusion of both should help demonstrate the robustness of the proposed effects. Furthermore, we argue that employees’ commitment to the changing organization provides an overall evaluative summary of their attitudes toward the organization during the organizational change, as well as acting as a mediator between leadership perceptions and behavioral reactions. Such indirect effects are also subject to the former leader's transformational leadership. 
With this approach, the current article makes several contributions. First, we uncover an important contingency that has been overlooked in prior transformational leadership research: how the effectiveness of a new leader's transformational leadership depends on the former leader's level of transformational leadership. Among the voluminous published studies in this area (for recent review, see Wang, Oh, Courtright, \& Colbert, 2011), how leader succession alters the effects of transformational leadership seldom are formally modeled. To understand this important source of variability, we specifically sample employees during leader succession and investigate the moderating role of the former leader in influencing employees' reactions to a new leader.

Second, leader succession and organizational change are often intertwined. The effects of leadership on employee reactions to change have received substantial scholarly interests, but the organizational change literature has not incorporated the potential influence of leader successions yet. This oversight suggests that our current theoretical understanding of the organizational change process is incomplete. We contribute to organizational change research by exploring how two key forces, the former leader and the new leader, jointly shape employees' reactions to organization change.

Third, we contribute to scant literature on leader succession. Prior empirical work has been either experimental or based on archival data, and has mainly focused on the new leader's entrance (e.g., Ndofor, Priem, Rathburn, \& Dhir, 2009; Ritter \& Lord, 2007; Sauer, 2011). The role of the former leader in the process of leader succession remains poorly understood (Hollenbeck, DeRue \& Nahrgang, 2015). From the lens of contrast effect theory, this study provides important empirical evidence in a theoretically relevant context (i.e., organizational 
change) to show that during leader succession, it is necessary to understand the influence of the former leader to fully uncover how the new leader influences individual outcomes.

\section{Theory and Hypotheses Development}

As a quote that Liberman, Boehm, Lyubomirsky, and Ross (2009, p. 666) cite says, “[A]lthough we don't live in the past, we live with the past.” Past experiences, whether positive or negative, inform our judgment and make us who we are now. The main thesis underlying the contrast effect is straightforward: past experiences serve as standards for comparison in determining reactions to present experiences (Frederick \& Loewenstein, 1999; Markman \& McMullen, 2003). A positive present is more positive when compared with a negative past; the same positive present is less positive when compared with a positive past.

We argue that the former leader's transformational leadership serves as a standard for comparison that determines the effectiveness of the new leader's transformational leadership. People use shortcuts or heuristics, such as representations of significant others, to make sense of each newly encountered other (Andersen \& Chen, 2002; Bargh, Chen, \& Burrows, 1996). For example, Ritter and Lord (2007) show that representations of the former leader get activated when followers try to make sense of a new, similar leader. When a former leader departs from the position that the new leader is taking over, the representations of both leaders should be cognitively accessible and directly comparable.

In an organizational change context, transformational leaders are effective because they can communicate why change is necessary, why it is important, and what to expect after the change; their exemplification, inspiration, and individualized attention also exert positive influences on employees during organizational change (Bommer et al., 2005; Herold et al., 2008; Hill et al., 2011; Seo et al., 2012). Organizational change involves a series of attempts to modify 
existing organizational structures, goals, technology, or relational patterns, and it requires employees to understand and adapt to these new structures and procedures. Therefore, it is not surprising that employees display different levels of behavioral resistance to or support for organizational change, reflecting their different levels of fear of the unknown, perceived or actual threat, lack of trust, and difficulty adapting to skill requirements (Iverson, 1996; Rafferty \& Griffin, 2006). Transformational leadership can generate awareness and acceptance of the purposes, goals, and new missions of the organization, stirring employees to look beyond their own self-interests for the good of the organization while still attending to each employee's emotional needs and personal development (Bass, 1985). Such behaviors then help reduce employees' behavioral resistance to change and even increase their behavioral support for the organizational change.

During leader succession, the new leader’s transformational leadership is observed and reacted to, relative to the level of the former leader's transformational leadership. When the standard for comparison (i.e., former leader's transformational leadership) is lower, employees should react more positively to the new leader's transformational leadership. In other words, the new leader's behaviors relate more strongly to employees' behavioral resistance to change (negatively) and support for change (positively). Transformational leadership behaviors by the new leader, such as communicating the meaning of the change to employees, troubleshooting initial change efforts, and leading employees to adapt functionally to new demands (Bommer et al., 2005; Herold et al., 2008), are more likely to have positive influences on employees. As suggested by Hollenbeck et al. (2015)'s theoretical model to leadership change, succession opportunities often arise when a team is experiencing conflict. The lower standard for comparison thus provides a fertile ground for the new leader to be transformational. On the other 
hand, if the standard for comparison instead is higher, employees likely exhibit weaker reactions to the new leader's transformational leadership. The former leader's high transformational leadership will be associated with a higher standard of comparison, so any level of transformational leadership from the new leader is likely to have a less positive impact (Frederick \& Loewenstein, 1999). This prediction is also consistent with substitutes for leadership theory, which posits that certain contextual factors are able to neutralize the effectiveness of leader behaviors (Kerr \& Jermier, 1978; Podsakoff, MacKenzie, \& Bommer, 1996). A highly transformational former leader serves as a "substitute" that weakens or neutralizes the influence of the new leader's transformational leadership. These theoretical observations lead to the following moderation hypothesis:

Hypothesis 1: The former leader's transformational leadership moderates the relationship between the new leader's transformational leadership and employees' (a) behavioral resistance to and (b) behavioral support for change. Specifically, when the former leader's transformational leadership is low, the new leader's transformational leadership has stronger effects than when the former leader's transformational leadership is high. Commitment to the changing organization serves as a mediating mechanism between the new leader's transformational leadership and employees' behavioral reactions to organizational change. Organizational commitment, defined as employees' attachment to the organization in general, is a well-studied construct in management research (e.g., Allen \& Meyer, 1990; Mowday, Steers, \& Porter, 1979). Commitment researchers identify more specific foci or referents, such as commitment to a person, a specific program, and most relevant to our paper, the organizational change (Fedor, Caldwell, \& Liu, 2006; Herscovitch \& Meyer, 2002; Herold et al., 2008). Consistent with Fedor et al. (2006), we contextualize organizational commitment to 
reflect employees' attitudes toward the changing organization—-that is, embracing the changes the organization is undertaking and expressing willingness to work on its behalf during the change period. To distinguish this construct from organizational commitment, we refer to it as commitment to the changing organization.

Transformational leadership, at its deepest level, actually transforms employees’ attitudes, values, and beliefs so that they regard the values and goals of the organizational change in ways aligned with their own values and goals (Shamir, House, \& Arthur, 1993). Commitment to the changing organization captures employee attitudes that may be antecedents to employee behaviors, such as behavioral resistance to or support for change (Carter, Armenakis, Feild, \& Mossholder, 2013; Furst \& Cable, 2008). Highly committed employees are motivated to act on behalf of the organization during the period of change, so they exhibit lower resistance and greater supportive behaviors toward the change (Herold et al., 2008; Herscovitch \& Meyer, 2002; Hill et al., 2012; van Knippenberg, Martin, \& Tyler, 2006). Like prior studies of transformational leadership (Paul, Costley, Howell, Dorfman, \& Trafimow, 2001; Sosik, 1999; van Knippenberg, van Knippenberg, De Cremer, \& Hogg, 2005), we also argue that transformational leadership influences employees' behaviors by affecting their attitudes. Thus, transformational leadership influences employees' behavioral reactions to change, through an elevated level of commitment to the changing organization.

Consistent with our moderation argument in the first hypothesis, we expect that the former leader's transformational leadership moderates the proposed indirect effects in the same direction. At lower levels of the former leader's transformational leadership, the indirect effects through commitment to the changing organization should be stronger. The comparison standard is relatively low, and the effect of the new leader's transformational leadership on commitment 
to the changing organization is relatively stronger. The overall indirect effects are thus strengthened. Similarly, at higher levels of the former leader's transformational leadership, the conditional indirect effects should be weaker. Therefore, we formulate our second hypothesis:

Hypothesis 2: The indirect effect of the new leader's transformational leadership on (a) behavioral resistance to and (b) behavioral support for change through commitment to the changing organization is moderated by the former leader's transformational leadership. The indirect effects are stronger when the former leader's transformational leadership is lower.

\section{Methods}

\section{Organizational Context}

We collected two rounds of survey data from a large, Chinese hospitality company that was implementing radical, discontinuous, and intentional organizational change (Weick \& Quinn, 1999). The company had operated in a mid-eastern city in China for more than 30 years. About a year before our data collection, its top management team decided that they would change their existing customer base. The corporation previously targeted institutional customers within the city but wanted to attract more mainstream customers through a series of strategic renewal efforts. As Beck, Brüderl, and Woywode (2008) suggest, addressing a new range of customers is one of the most challenging forms of organizational change. To effect this change, the hospitality company must counteract the "taken-for-granted" practices that have accumulated for decades and adopt a very different business strategy. Right before our data collection, the company had begun to plan a brand new hotel in a bigger, nearby city, based upon the new business strategy. It was one of the most prominent moves in the overall strategic reorientation. Many frontline leaders in our research site were transferred to this new hotel, causing many vacancies to be 
filled by new leaders. In addition, changes took place in almost every aspect of the daily management practices, including product, pricing, recruitment, training, and work routines. Therefore, change was a very salient concept to the employees at the time of our data collection.

\section{Sample and Procedures}

With the assistance of the human resource manager, we identified 28 teams that had experienced a leader succession in the previous four weeks. We excluded employees who had shorter tenure than the new leader, to ensure all participants were able to provide ratings for both the former and the new leader. This step resulted in a total of 271 potential participants. We designed a short time lag of two weeks to separate ratings of the former leader from ratings of the new leader. With this design, we achieved a very low attrition rate (less than 3\%).

Two authors and a team of trained research assistants were on site to explain the purpose of the study, assure confidentiality, distribute and collect the questionnaires. Participants filled out questionnaires during or right after their shifts, on the company's premises. Each participant received 30 RMB ( $\sim 5$ USD) if they participated in both rounds. Leaders who rated more than four employees received 10 RMB ( 1.7 USD) for each additional rating. After matching employee surveys and leader surveys, our final sample consisted of 203 valid employee surveys (75.4\% response rate) and 22 valid leader surveys (78.6\% response rate). Among these respondents, $28 \%$ were women; $19 \%$ had a bachelor's degree or above, $66 \%$ had a high school degree, and 25\% had a junior high school education or less. The mean age was 26.7 years, and the mean tenure with the company was 3.2 years.

\section{Measures}

All surveys were conducted in Chinese. To ensure equivalence, all items were translated into Chinese and then independently translated back into English. All measures used 7-point 
Likert-type scales ( 1 = strongly disagree, 7 = strongly agree). Employees rated the former leader's transformational leadership at time 1, and then rated the new leader's transformational leadership and reported their commitment to the changing organization at time 2. New leaders rated employees' resistance to and support for change behaviors at time 2.

Transformational Leadership. Both the former and the new leaders' transformational leadership behaviors were measured by the 23-item transformational leadership scale developed by Podsakoff, MacKenzie and Fetter (1990). The former leader was rated at time 1; the new leader was rated at time 2 . This time lag helps reduce any confusion between the two leaders and allows up to six weeks for employees to interact with their new leader and observe his or her transformational leadership behaviors. A sample item from this scale is, "My former [new] leader inspires others with his/her plans for the future.” The scale reliabilities for the new and former leaders were .97 and .92, respectively. Because of the potentially nested structure, we also calculated ICC(1) values for this measure, which were .14 for the former leader and .19 for the new leader.

One assumption of this study is that transformational leaders support organizational change. To test this assumption, we asked employees about their perceptions of both leaders' issue-selling behaviors, on a scale developed by Schriesheim and Hinkin (1990). This scale assessed the degree to which leaders sold the issues related to organizational change to them, such as with an item asking to what extent "the leader presented information in support of the organizational change.” The issue-selling scales correlated with the former leader's $(\mathrm{r}=.67, p$ $<.05)$ and new leader's $(\mathrm{r}=.76, p<.05)$ transformational leadership behaviors. Therefore, at least in our study context, we find support for the assumption that transformational leaders are in support of this organizational change. 
Commitment to the Changing Organization. We transformed Allen and Meyer’s (1990) three organizational commitment items to measure organizational changes. The instruction sentence of this measure is, “p[P]lease reflect upon your experience during this organizational change, and rate your attitudes toward the changing organization”, and the three items were, “I really feel as if this organization's problems are my own," "I feel a strong sense of belonging to my organization,” and “I feel emotionally attached to the organization.” The reliability estimate for this scale was .81 .

Behavioral Resistance and Support to Change. New leaders rated each employee’s behavioral resistance to and support for change at time 2, using a scale developed and validated by Seo et al. (2012). The original scales were self-reports, but we modified them into a supervisor-rated format. A sample item for behavioral resistance was, "When this employee has been asked to do new things as part of the change, he/she has just kept to what he/she had been

doing before the change.” A sample item for behavioral support was, “This employee has put in a good deal of effort in trying to do what he or she can to make the change succeed.” The Cronbach’s alpha values for behavioral resistance to and support for change were .85 and .81, respectively. The ICC(1) values were .39 for resistance and .29 for support.

\section{Data Analytic Strategies and Results}

The descriptive statistics and intercorrelations are in Table 1. To examine the factor structure and discriminant validity among the variables, we conducted a confirmatory factor analysis (CFA) in Mplus 7.0 (Muthén \& Muthén, 2012). Considering the many items in the transformational leadership scale, we formed six parcels to correspond to the six dimensions of transformational leadership, help simplify the measurement model, and increase statistical power (Little, Cunningham, Shahar, \& Widaman, 2002). The results of the CFA show that all factor 
loadings are statistically significant, with reasonable overall measurement model fit $\left(\chi^{2}[53]=\right.$ 165.65; confirmatory fit index $[\mathrm{CFI}]=.91$; Tucker-Lewis index $[\mathrm{TLI}]=$.89; root mean square error of approximation [RMSEA] $=.10$ with $90 \%$ confidence interval [CI] [.09, .13]; square root mean residual $[\mathrm{SRMR}]=.06$ ). We also ran a measurement invariance test, using the measures of the former leader's and the new leader's transformational leadership. With this test, we make sure that any difference between the two measures is quantitative instead of qualitative (Vandenberg \& Lance, 2000). It rules out the possibility that employees’ understanding of transformational leadership as a construct in time 2 (toward the new leader) is conceptually different from their understanding in time 1 (toward the former leader). The results supported both configural $\left(\chi^{2}[21]=71.19 ; \mathrm{CFI}=.97 ; \mathrm{TLI}=.96\right.$; RMSEA $=.11$ with $90 \%$ CI $[.08, .14]$; $\mathrm{SRMR}=.04)$ and metric $\left(\chi^{2}[23]=72.07 ; \mathrm{CFI}=.97 ; \mathrm{TLI}=.96 ; \mathrm{RMSEA}=.10\right.$ with $90 \% \mathrm{CI}$ $[.08, .13]$; SRMR $=.07)$ invariance. Even the means of these two constructs were invariant from each other $(\Delta \mathrm{M}=.02, \mathrm{n} . \mathrm{s}$.$) . Thus, we are able to establish measurement invariance for the former$ leader's and the new leader's transformational leadership. It's important to note that, however, interpretations of these CFA and measurement invariance findings require some caution, because our nested data violate the independence assumption.

Insert Table 1 about here

We are primarily interested in individual phenomena, but our data are nested in nature. To account for potential biases caused by this data structure, we specify random intercept models that model behavioral resistance and behavioral support at both within- and between-levels for all hypotheses. Estimating the random intercepts for these two variables is consistent with our intention to study supervisors' differential ratings of their subordinates. Transformational 
leadership for the two leaders was only modeled within-level though, because we are interested in the individual perceptions of the leaders instead of deviations from the group mean. Also, as reported, the ICC(1) values of transformational leadership were substantially lower than those of supervisor-rated behavioral resistance and support, thus further justifying our model specification.

Our first hypothesis concerns the interaction between the level of transformational leadership of the former leader and the new leader on behavioral resistance (Hypothesis 1a) and behavioral support for change (Hypothesis 1b). The regression results in Table 2 show that the former leader's transformational leadership significantly moderates the relationship between the new leader's transformational leadership and employees' resistance $(\omega=-.22 ; p<.05)$ and support for change $(\omega=.21 ; p<.01)$. To facilitate the interpretation, we plot the interaction patterns in Figure 1 using the LOOP command in Mplus 7.0. As Figure 1a reveals, when the former leader is high in transformational leadership (+1 SD), the relationship between the new leader's transformational leadership and resistance to change does not differ statistically from 0 $(\beta=-.12 ; n$.s. $)$. When the former leader's transformational leadership is low though ( $-1 \mathrm{SD})$, the relationship is negative and significant $(\beta=-.47 ; p<.01)$, suggesting that the new leader's transformational leadership behavior decreases followers’ resistance to change behaviors. Similarly, Figure 1b shows that the relationship of the new leader's transformational leadership with follower support for change is stronger when the former leader's transformational leadership behavior is low $(\beta=.33 ; p<.05)$ rather than high $(\beta=.12$; n.s.). This pattern is consistent with our expectations, in support of Hypothesis 1a and 1b.

Insert Table 2, Figure 1a and 1b about here 
In Hypothesis 2 we propose a mediation effect, such that the effects of the new leader's transformational leadership on employees’ behavioral resistance (Hypothesis 2a) and behavioral support for change (Hypothesis 2b), through their commitment to the changing organization, is subject to the level of the former leader's transformational leadership. To test the conditional indirect effects, we estimated multilevel indirect effects following a 1-1-1 model with a fixed slope (Preacher, Zyphur, \& Zhang, 2010). Then we calculated the strength of the indirect effect at 1 standard deviation below and above the mean of the moderator, using the procedures suggested by Preacher, Rucker, and Hayes (2007). The results are in Table 2. For Hypothesis 2a, the bootstrapped indirect effect is significant when the former leader's transformational leadership is low $(\beta=-.18 ; p<.01)$ but not when it is high $(\beta=-.02 ; n . s$.$) . For Hypothesis 2 \mathrm{~b}$, the indirect effect is not statistically significant in both the low condition $(\beta=.10 ; n . s)$ and the high condition ( $\beta=.03$; n.s.). Yet, consistent with our expectations, the coefficient of the low condition is still larger than that of the high condition. Thus, Hypothesis $2 a$ was supported but $2 b$ was not.

\section{Discussion}

In this study, we develop a theoretical model of leader succession during organizational change and show that when the former leader's transformational leadership is higher, the new leader's transformational leadership tends to have weaker effects on behavioral resistance to and support for change. When it is lower, the new leader's transformational leadership exerts stronger effects. We find mixed support for conditional indirect effects. The indirect effect of the new leader’s transformational leadership on employees' resistance to change through commitment to the changing organization is stronger when the former leader's transformational 
leadership is lower. However, the conditional indirect effect failed to reach statistical significance when support for change was the dependent variable.

\section{Theoretical Contributions}

This study contributes to the organizational change literature by incorporating the former leader into our understanding of how leader behaviors influence important employee outcomes during organizational change. We find evidence that effects of the former leader continued to be salient during employees' initial experience with the new leader. The inclusion of the former leader's transformational leadership accounts for meaningful additional variance in explaining important employee outcomes during organizational change. Even if the former leader does not play a leadership role in the team any longer, he or she continues to have a lingering influence on employees' reactions to organizational change. The effects on behavioral resistance to change were stronger than behavioral support for change, suggesting that promoting desirable behaviors should be more difficult than correcting undesirable behaviors.

Furthermore, prior change literature has established that transformational leadership positively influences commitment and behavioral support but negatively influences behavioral resistance to change (e.g., Bommer et al., 2005; Herold et al., 2008; Hill et al., 2011; Oreg \& Berson, 2011; Seo et al., 2012). When the former leader is high in transformational leadership, these well-established relationships were washed out. The highly transformational former leader sets a higher standard for reactions to the new leader, neutralizing the effects of the new leader's transformational leadership. It thus serves as a boundary condition on the effects of transformational leadership, which might generalize to other contexts.

Finally, the current article is one of the few empirical studies to shed light on the former leader's influence on employees' reactions during the initial term of the new leader. As Ballinger 
and Schoorman (2007) argue, a lack of empirical research at the individual level has led to unwarranted assumptions that employees always react negatively to leader succession. We show instead that employees' reactions depend on the level of transformational leadership displayed by the former leader. The combination of a less transformational former leader and a transformational new leader actually results in more positive employee reactions.

\section{Practical Contributions}

A first practical implication of our study is the importance of a transformational leadership style during organizational change. Various researchers make similar points (e.g., Bommer et al., 2005; Herold et al., 2008; Hill et al., 2011), but our results go further and show that a new leader who is transformational can compensate for a former leader who failed to display transformational leadership behaviors, at least when it comes to inspiring employees' commitment. The lingering effects of the former leader who displayed little transformational leadership can be turned into a benefit in this sense. Our results also suggest ways that an organization might optimize change outcomes if there is a lack of enough transformational leaders to fill all of its open leadership positions. Since transformational leaders likely have more impacts if the former leader displayed lower levels of transformational leadership, those are the teams to which highly transformational leaders should be assigned.

A second practical implication of our research is that the contrast between a team's current leader and its former leader should be made salient to employees when the new leader is more transformational than the former. Tactics ranging from subtle verbal comparisons to formalized surveys, with previous leader behavior as a benchmark, could be effective. Due to the contrast effect, making positive differences more salient should increase the effectiveness of the 
new leader's transformational behavior on followers' commitment to and support for the organizational change (Hollenbeck et al., 2015).

Finally, with regard to evaluations of the new leader, our results suggest that it will be difficult for a new leader to have a strong positive impact on her or his team if the former leader already was transformational. In this case, the new leader may be only capable of maintaining rather than “transforming” employees' attitudes and behaviors, regardless of the level of the new leader's actual transformational leadership behaviors. Managers should be aware that the style of a team's former leader may limit the opportunity for the new leader to demonstrate his or her ability to influence the unit toward greater acceptance of organizational goals. Such unintended effects due to the contrast between the former leader and the new leader can be particularly salient during the early stage of leader succession.

\section{Limitations and Further Research}

The present study has several limitations that should be addressed by further research. First, the moderating effects of the former leader's succession may fade over time, but we could not establish the rate of decay with our current study design. We carefully designed the timing of our study to capture the succession process, but our non-longitudinal design cannot speak to the duration of the former leader's influence on the effectiveness of the new leader. Additional research should employ a longitudinal design to examine the developmental trajectory of employee outcomes for leader successions.

Second, our primary research interest is how leader succession influences employees’ reactions during organizational change. Limited by this research scope, we do not examine factors that might contribute to the success or failure of the leader succession itself. For example,

further research could explore whether employees are informed of the leader succession ahead of 
time, how the individual attributes of the new leader and the former leader interact, and whether different reasons for leader succession (e.g., involuntary turnover, internal promotion/demotion or rotation) alter the effectiveness of the leader succession. We encourage research in all of these directions.

Third, a direct measure of commitment to change (e.g., Herscovitch \& Meyer, 2002), rather than the more mixed "commitment to the changing organization" measure in our study, may provide a stronger test of leader succession during organizational change. Yet, previous empirical findings (Fedor et al., 2006) indicate that the commitment foci of “organization” and "change” are highly correlated. The major strategic change that created the context for this study makes the distinction even less clear, because the entire organization was undergoing change. Nonetheless, future research might use commitment to the specific change initiative, rather than mixing commitment to the organization and the change initiative within a single scale.

\section{Conclusion}

In this study, we found that a former leader with low transformational leadership actually enhanced the effects of the new leader's transformational leadership on employee outcomes during organizational change. Such findings not only fill a gap in organizational change literature but also add to literature on the moderators of transformational leadership. Our findings suggest that incorporating the former leader's behavior as a moderator adds meaningful variance that can explain employees’ reactions during organizational change. 


\section{References}

Allen, N. J., \& Meyer, J. P. (1990). The measurement and antecedents of affective, continuance and normative commitment to the organization. Journal of Occupational Psychology, 63, $1-18$.

Andersen, S. M., \& Chen, S. (2002). The relational self: an interpersonal social-cognitive theory. Psychological Review, 109(4), 619-645.

Arthaud-Day, M. L., Certo, S. T., Dalton, C. M., \& Dalton, D. R. (2006). A changing of the guard: Executive and director turnover following corporate financial restatements. Academy of Management Journal, 49, 1119-1136.

Ballinger, G. A., \& Schoorman, F. D. (2007).Individual reactions to leadership succession in workgroups. Academy of Management Review, 32, 118-136.

Barker III, V. L., Patterson Jr., P. W., \& Mueller, G. C. (2001). Organizational causes and strategic consequences of the extent of top management team replacement during turnaround attempts. Journal of Management Studies, 38, 235-270.

Bargh, J. A., Chen, M., \& Burrows, L. (1996). Automaticity of social behavior: Direct effects of trait construct and stereotype activation on action. Journal of Personality and Social Psychology, 71(2), 230-244.

Bass, B.M. (1985). Leadership and performance beyond expectations. New York: The Free Press.

Bass, B. M., \& Riggio, R. E. (2006). Transformational leadership (2 ${ }^{\text {nd }}$ ed.). Mahwah, NJ: Lauren Erlbaum Associates.

Beck, N., Brüderl, J., \& Woywode, M. (2008).Momentum or deceleration? Theoretical and methodological reflections on the analysis of organizational change. Academy of Management Journal, 51, 413-435.

Bommer, W. H., Rich, G. A. \& Rubin, R.S. (2005). Changing attitudes about change: Longitudinal effects of transformational leader behavior on employee cynicism about organizational change. Journal of Organizational Behavior, 26, 733-753. 
Carter, M. Z., Armenakis, A. A., Feild, H. S., \& Mossholder, K. W. (2013).Transformational leadership, relationship quality, and employee performance during continuous incremental organizational change. Journal of Organizational Behavior, 34: 942-958.

Fedor, D. B., Caldwell, S., \& Herold, D. M. (2006). The effects of organizational changes on employee commitment: A multilevel investigation. Personnel Psychology, 59(1), 1-29.

Frederick, S. \& Loewenstein, G. (1999). Hedonic adaptation. In Kahneman, D., Diener, E.D., \& Schwatz, N. (eds.) Well-being: The foundations of hedonic psychology. (pp. 302-329). New York: Russell Sage Foundation.

Furst, S. A., \& Cable, D. M. (2008). Employee resistance to organizational change: Managerial influence tactics and leader-member exchange. Journal of Applied Psychology, 93, 453.

Giambatista, R., Rowe, W. G. and Riaz, S. (2005). Nothing succeeds like succession: A critical review of leader succession literature since 1994. The Leadership Quarterly, 16: 963-991.

Gilmore, T. N. (2003). Making a leadership change ( $2^{\text {nd }}$ Ed.). Lincoln, NE: iUniverse.

Herold, D.M., Fedor, D.B., Caldwell, S., \& Liu, Y. (2008). The effects of transformational and change leadership on employees’ commitment to change: A multilevel study. Journal of Applied Psychology, 93, 346-357.

Herscovitch, L., \& Meyer, J. P. (2002). Commitment to organizational change: Extension of a three-component model. Journal of Applied Psychology, 87, 474-487.

Hill, N.S., Seo, M. G., Kang, J. H., \& Taylor, S. M. (2012). Building employee commitment to change across organizational levels: The influence of hierarchical distance and direct managers' transformational leadership. Organizational Science, 23, 758-777.

Hollenbeck, J. R., DeRue, D. S., \& Nahrgang, J. D. (2015). The opponent process theory of leadership succession. Organizational Psychology Review, 5(4), 333-363.

Iverson, R. D. (1996). Employee acceptance of organizational change: the role of organizational commitment. International Journal of Human Resource Management, 7, 122-149.

Kanter, R. M., Stein, B. A. \& Jick, T. D. (2003). Challenge of organizational change: How companies experience it and leaders guide it. New York: Free Press. 
Kerr, S., \& Jermier, J. M. (1978). Substitutes for leadership: Their meaning and measurement. Organizational Behavior and Human performance, 22, 375-403.

Kesner, I. F., \& Sebora, T. C. (1994). Executive succession: Past, present and future. Journal of Management, 20, 327-372.

Liberman, V., Boehm, J. K., Lyubomirsky, S., \& Ross, L. D. (2009). Happiness and memory: affective significance of endowment and contrast. Emotion, 9(5), 666-680.

Little, T. D., Cunningham, W. A., Shahar, G., \& Widaman, K. F. (2002). To parcel or not to parcel: Exploring the question, weighing the merits. Structural Equation Modeling, 9(2), 151-173.

Markman, K. D., \& McMullen, M. N. (2003). A reflection and evaluation model of comparative thinking. Personality and Social Psychology Review, 7(3), 244-267.

Mowday, R. T., Steers, R. M., \& Porter, L. W. (1979). The measurement of organizational commitment. Journal of Vocational Behavior, 14, 224-247.

Muthén, L. K., \& Muthén, B. O. (2012). Mplus 7.0. Los Angeles, CA: Muthén \& Muthén.

Ndofor, H. A., Priem, R. L., Rathburn, J. A., \& Dhir, A. K. (2009). What does the new boss think? How new leaders' cognitive communities and recent “top-job” success affect organizational change and performance. The Leadership Quarterly, 20, 799-813.

Oreg, S., \& Berson, Y. (2011). Leadership and employees’ reactions to change: The role of leader's personal attributes and transformational leadership style. Personnel Psychology, 64, 627-659.

Paul, J., Costley, D. L., Howell, J. P., Dorfman, P. W., \& Trafimow, D. (2001). The effects of charismatic leadership on followers' self-concept accessibility. Journal of Applied Social Psychology, 31, 1821-1842.

Podsakoff, P. M., MacKenzie, S. B., \& Bommer, W. H. (1996).Meta-analysis of the relationships between Kerr and Jermier's substitutes for leadership and employee job attitudes, role perceptions, and performance. Journal of Applied Psychology, 81, 380-399. 
Podsakoff, P.M., MacKenzie, S.B., \& Fetter, R. (1990). Transformational leader behaviors and their effects on followers' trust in leader, satisfaction, and organizational citizenship behaviors. Leadership Quarterly, 1, 107-142.

Preacher, K. J., Zyphur, M. J., \& Zhang, Z. (2010). A general multilevel SEM framework for assessing multilevel mediation. Psychological Methods, 15(3), 209-233.

Preacher, K. J., Rucker, D. D., \& Hayes, A. F. (2007). Addressing moderated mediation hypotheses: Theory, methods, and prescriptions. Multivariate Behavioral Research, 42(1), $185-227$.

Rafferty, A.E., M.A. Griffin. (2006). Perceptions of organizational change: A stress and coping perspective. Journal of Applied Psychology, 91, 1154-1162.

Ritter, B. A. \& Lord, R. G. (2007). The impact of previous leaders on the evaluation of new leaders: An alternative to prototype matching. Journal of Applied Psychology, 92, 16831695.

Sauer, S. J. (2011). Taking the reins: The effects of new leader status and leadership style on team performance. Journal of Applied Psychology, 96, 574-587.

Schriesheim, C. A., \& Hinkin, T. R. (1990). Influence tactics used by subordinates: A theoretical and empirical analysis and refinement of the Kipnis, Schmidt, and Wilkinson subscales. Journal of Applied Psychology, 75(3), 246-257.

Seo, M., Taylor, M. S., Hill, S. N., Zhang, X., Tesluk, P., \& Lorinkova, N. M. (2012). The role of affect and leadership during radical organizational change. Personnel Psychology, 65, 121-165.

Shamir, B., House, R. J., \& Arthur, M. B. (1993). The motivational effects of charismatic leadership: A self-concept based theory. Organization Science, 4, 577-594.

Sosik, J. J. (1999). Self-concept based aspects of the charismatic leader: More than meets the eye. The Leadership Quarterly, 9, 503-526.

Vandenberg, R. J., \& Lance, C. E. (2000). A review and synthesis of the measurement invariance literature: Suggestions, practices, and recommendations for organizational research. Organizational Research Methods, 3(1), 4-70. 
van Knippenberg, B., Martin, L., \& Tyler, T. (2006). Process-orientation versus outcome orientation during organizational change: The role of organizational identification. Journal of Organizational Behavior, 27, 685-704.

van Knippenberg, B., van Knippenberg, D., De Cremer, D., \& Hogg, M. A. (2005). Research in leadership, self, and identity: A sample of the present and a glimpse of the future. The Leadership Quarterly, 16, 495-499.

Wang, G., Oh, I. S., Courtright, S. H., \& Colbert, A. E. (2011). Transformational leadership and performance across criteria and levels: A meta-analytic review of 25 years of research. Group \& Organization Management, 36, 223-270.

Watkins, M. (2003).The first 90 days: Critical success strategies for new leaders at all levels. Boston, MA: Harvard Business School Press.

Weick, K. E., \& Quinn, R. E. (1999). Organizational change and development. Annual Review of Psychology, 50(1), 361-386. 
Table 1

Descriptive Statistics and Correlations of Variables

\begin{tabular}{llllllllll}
\hline \multicolumn{1}{c}{ Variables } & $\mathrm{M}$ & $\mathrm{SD}$ & 1 & 2 & 3 & 4 & 5 \\
\hline 1 & Transformational leadership new leader & 4.76 & 0.91 & $(.97)$ & & & & \\
2 & Transformational leadership former leader & 4.77 & 0.98 & $.54^{* *}$ & $(.92)$ & & & \\
3 & Commitment to the changing organization & 5.36 & 1.33 & $.48^{* *}$ & $.43^{* *}$ & $(.81)$ & & \\
4 & Behavioral resistance to change & 3.09 & 1.30 & $-.19^{* *}$ & -.10 & $-.23^{* *}$ & $(.85)$ & \\
5 & Behavioral support to change & 4.59 & 1.14 & $.19^{* *}$ & $.22^{* *}$ & $.27^{* *}$ & $-.27^{* *}$ & $(.81)$ \\
\hline
\end{tabular}

Notes. $\mathrm{N}=203$. Coefficients in brackets are Cronbach's alpha values.

${ }^{* *} p<.01$ (two-tailed) 


\section{Table 2}

Unstandardized Estimates of Moderation and Conditional Indirect Effects

\begin{tabular}{|c|c|c|c|c|}
\hline \multicolumn{5}{|l|}{ Within Group Regression Coefficients } \\
\hline & \multicolumn{2}{|c|}{ Behavioral Resistance to Change (H1a) } & \multicolumn{2}{|c|}{ Behavioral Support for Change (H1b) } \\
\hline Transformational leadership new leader & \multicolumn{2}{|l|}{$-.26(.12)^{*}$} & \multicolumn{2}{|l|}{$.11(.09)$} \\
\hline Transformational leadership former leader & \multicolumn{2}{|l|}{$.06(.09)$} & \multicolumn{2}{|l|}{$-.06(.09)$} \\
\hline New leadership $\times$ Former leadership & \multicolumn{2}{|l|}{$.21(.05)^{* *}$} & \multicolumn{2}{|c|}{$-.22(.10)^{*}$} \\
\hline \multicolumn{5}{|l|}{ Between Group Mean and Variance } \\
\hline Mean & \multicolumn{2}{|c|}{$3.83(.70)^{* *}$} & \multicolumn{2}{|c|}{$4.41(.16)^{* *}$} \\
\hline Variance & \multicolumn{2}{|l|}{$0.53(.27)^{*}$} & \multicolumn{2}{|c|}{$0.39(.16)^{*}$} \\
\hline \multicolumn{5}{|c|}{ Conditional indirect model through commitment to the changing organization } \\
\hline & \multicolumn{2}{|c|}{ Behavioral Resistance to Change (H2a) } & \multicolumn{2}{|c|}{ Behavioral Support for Change (H2b) } \\
\hline & Estimates & Bootstrapped 95\% CI & Estimates & Bootstrapped 95\% CI \\
\hline Low transformational leadership former leader & $-.18(.08)^{* *}$ & {$[-0.32,-0.05]$} & $.10(.03)$ & {$[-0.02,0.21]$} \\
\hline High transformational leadership former leader & $-.02(.03)$ & {$[-0.07,0.04]$} & $.03(.02)$ & {$[-0.06,0.13]$} \\
\hline
\end{tabular}

Notes. $\mathrm{N}=$ 203. H1 = Hypothesis 1 model; H2 = Hypothesis 2 model.

$* * p<.01 . * p<.05$. 


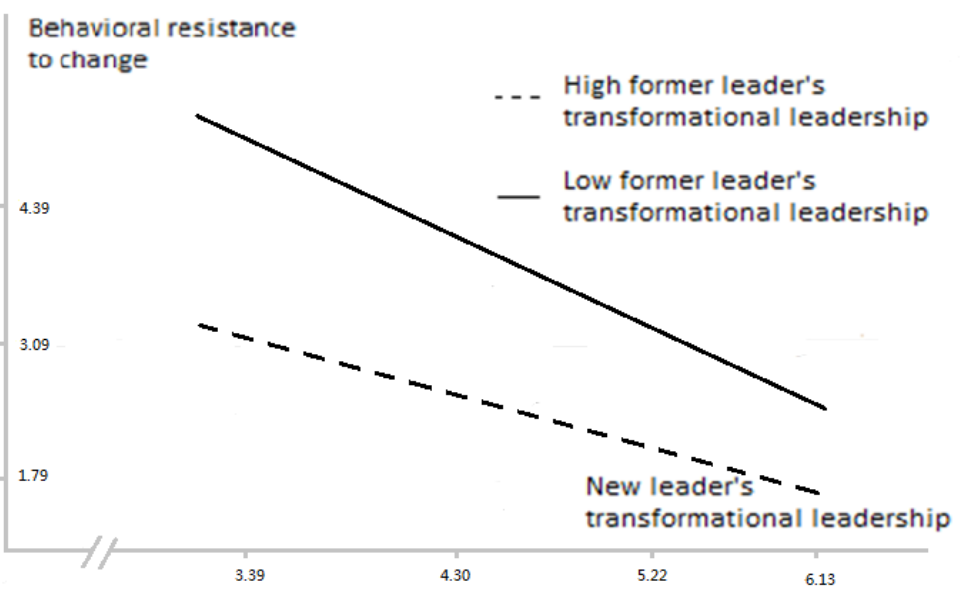

Figure 1a. Interaction plot of behavioral resistance to change as the outcome.

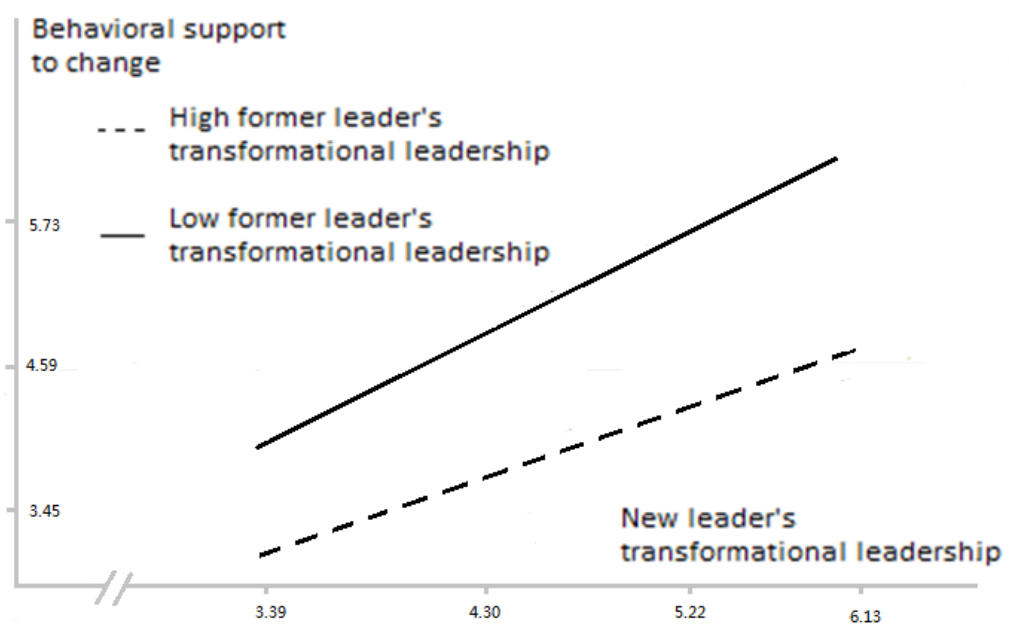

Figure $1 b$. Interaction plot of behavioral support for change as the outcome. 